\title{
PERBANDINGAN SEGMENTASI MENGGUNAKAN GREENPLATE DAN DISCRETE COSINE TRANSFORM PADA OBYEK BERBASIS GREENSCREEN
}

\author{
Heri Susanto ${ }^{1)}$, Jamal ${ }^{2}$, Dwi Yanto ${ }^{3)}$ \\ Manajemen Informatika, AMIK Taruna Probolinggo \\ J1. Raya Leces Nomer A3 Leces Probolinggo 67202 \\ Telp. (0335) 681497 Fax (0335) 681497 \\ E-mail : herisusanto@amik-taruna.ac.id ${ }^{1}$, jamal@amik-taruna.ac.id ${ }^{2}$, \\ dwiyanto@amik-taruna.ac.id $\left.{ }^{3}\right)$
}

\begin{abstract}
ABSTRAK
Segmentasi citra merupakan salah satu topik penting dalam bidang pengolahan citra digital yang dapat ditemukan dalam perbagai bidang riset citra. Masing-masing jenis citra memiliki pendekatan berbeda dalam penerapan proses segmentasi. Banyak metode yang dapat digunakan untuk proses segmentasi, misalnya dengan menggunakan threshold, pendeteksian tepi, transformasi watershed ataupun metode yang lain. Dalam penelitian ini membandingkan metode segementasi menggunakan Discrete Cosine Transform (DCT) dan Greenplate. Pengukuran menggunakan perbandingan nilai MSE (Mean Square Error) pada kedua metode terhadap citra asli. Hasil penelitian menunjukkan penurunan MSE dengan menggunakan metode Discrete Cosine Transformasi (DCT) ini. Kesimpulan dengan menggunakan Discrete Cosine Transform dapat memperbaiki segmentasi obyek berbasis Greenscreen.
\end{abstract}

Kata Kunci: Discrete Cosine Transformasi (DCT), Segmentasi, Mean Square Error (MSE)

\section{ABSTRACT}

Image segmentation is one of the important topics in the field of digital image processing which can be found in various fields of image research. Each type of image has a different approach in applying the segmentation process. Many methods can be used for the segmentation process, for example by using threshold, edge detection, watershed transformation or other methods. In this study comparing the segementation method using Discrete Cosine Transform (DCT) and Greenplate. Measurements using a comparison of MSE (Mean Square Error) values on both methods against the original image. The results showed a decrease in MSE using this Discrete Cosine Transformation (DCT) method. Conclusion using Discrete Cosine Transform can improve Greenscreen-based object segmentation.

Keywords: Discrete Cosine Transformasi (DCT), Segmentation, Mean Square Error (MSE)

\section{PENDAHULUAN}

Pengolahan citra merupakan salah satu cara untuk memperbaiki kualitas citra sehingga mudah diinterpretasi oleh manusia maupun mesin. Beberapa field research terkait dengan pengolahan data citra, antara lain grafika komputer (computer grafik), pengolahan citra (image processing), dan pengenalan pola (pattern recognition atau image interpretation). Pengolahan citra dilakukan dengan men-transformasikan citra menjadi citra lain yang mempunyai kualitas lebih baik yang operasinya meliputi perbaikan kualitas citra (image enhancement),
pemugaran citra (image restoration),
pemampatan citra (image compression),
segmentasi citra (image segmentation),
analisis citra (image analysis), dan rekontruksi citra [1]. Secara umum teknik pengolahan citra dikelompokkan ke dalam dua domain, yaitu domain spasial dan domain spectrum. Teknik pemrosesan domain spasial didasarkan pada manipulasi piksel dalam citra secara langsung, sehingga membutuhkan waktu yang sangat lama dalam memproses tetapi tidak tahan terhadap serangan. 
Sedangkan pada domain frekuensi didasarkan pada manipulasi terhadap transformasi fourier pada suatu citra, sehingga membutuhkan beberapa tahap pemrosesan, namun tahan terhadap serangan. Salah satu metode domain frekuensi citra adalah discrete cosine transform (DCT).

Discrete cosine transform adalah sebuah fungsi dua arah yang memetakan himpunan $\mathrm{N}$ buah bilangan real menjadi himpunan $\mathrm{N}$ buah bilangan real.

\section{METODE}

Discrete Cosine Transform (DCT) biasa digunakan untuk mengubah sebuah sinyal menjadi komponen frekuensi dasarnya. DCT pertama kali diperkenalkan oleh Ahmed, Natarajan dan Rao pada tahun 1974 dalam makalahnya yang berjudul "On image processing and a discrete cosine transform" [5].

DCT mempunyai dua sifat utama untuk kompresi citra dan video yaitu:

1. Mengkonsentrasikan energi citra ke dalam sejumlah kecil koefisien (energi compaction).

2. Meminimalkan saling ketergantungan diantara koefisien-koefisien (decorrelation).

Discrete Cosine Transform dari sederet $n$ bilangan real $s(x), x=0, \ldots, n-1$, dirumuskan sebagai berikut:

$$
S(u)=\sqrt{2 / n} C(u) \sum_{x=0}^{n-1} s(x) \cos \frac{(2 x+1) u \pi}{2 n}
$$

dengan:

$$
\mathrm{u}=0, \ldots, \mathrm{n}-1
$$

Dimana:

$$
C(u)=\left\{\begin{array}{l}
2^{-1 / 2}, \\
1
\end{array}\right.
$$

Setiap element dari hasil transformasi $S(u)$ merupakan hasil dot product atau inner product dari masukan $s(x)$ dan basis vektor. Faktor konstanta dipilih sedemikian rupa sehingga basis vektornya orthogonal dan ternormalisasi. DCT juga dapat diperoleh dari produk vektor (masukan) dan $n \times n$ matriks orthogonal yang setiap barisnya merupakan basis vektor. Delapan basis vektor untuk $n=$ 8 dapat dilihat pada gambar 2. Setiap basis vektor berkorespondensi dengan kurva sinusoid frekuensi tertentu.

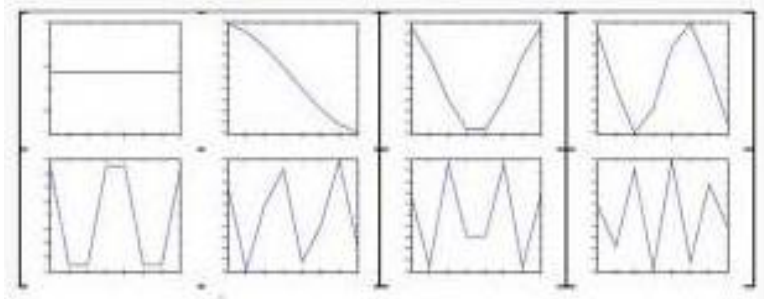

Gambar 1. Basis Color Vector for DCT

Barisan $s(x)$ dapat diperoleh lagi dari hasil transformasi $S(u)$ dengan menggunakan inverse discrete cosine transform (IDCT), yang dirumuskan sebagai berikut:

$$
S(u)=\sqrt{2 / n} \sum_{u=0}^{n-1} S(u) C(u) \cos \frac{(2 x+1) u \pi}{2 n}
$$

dengan:

$$
\mathrm{u}=0, \ldots, \mathrm{n}-1
$$

dimana:

$$
\text { , } C(u)=\left\{\begin{array}{l}
2^{-1 / 2}, \\
1
\end{array}\right.
$$

Persamaan diatas menyatakan $s$ sebagai kombinasi linier dari basis vektor. Koefisien adalah elemen transformasi $S$, yang mencerminkan banyaknya setiap frekuensi yang ada didalam masukan $s$ [3].

Discrete Cosine Transform merepresentasi kan sebuah citra dari penjumlahan sinusoida dari magnitude dan frekuensi yang berubahubah. Sifat dari DCT adalah mengubah informasi citra yang signifikan dikonsentrasikan hanya pada beberapa koefisien DCT. Oleh karena itu DCT sering digunakan untuk kompresi citra seperti pada JPEG. Koefisien discrete cosine transform (DCT) menggambarkan kandungan distribusi frekuensi pada gambar. Transformasinya 
memiliki sifat yang kompak sedemikian hingga informasi gambar dapat tersimpan dalam sejumlah kecil koefisien hasil transformasi. Untuk alasan praktis, biasanya dipilih ukuran blok yang merupakan kelipatan pangkat 2. DCT bersifat reversible sedemikian hingga koefisien hasil transformasi DCT yang tidak diolah lebih lanjut bisa menghasilkan kembali gambar rekonstruksi sesuai dengan aslinya tanpa cacat. Gambar hasil rekontruksi ini bisa dipandang sebagai kombinasi linear dari fungsi basis DCT. Contoh fungsi basis DCT dua dimensi untuk ukuran matriks yang berbeda akan menghasilkan fungsi basis yang berbeda yang di tampilkan di Gambar 3 .

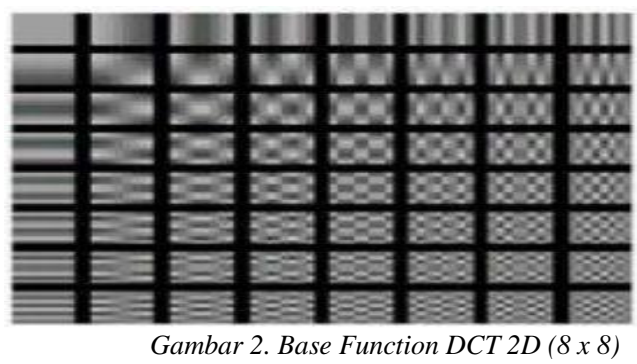

\section{Discrete Cosine Transform - 1 Dimension}

DCT dari sederet bilangan real $\mathrm{d}(\mathrm{x}), \mathrm{x}=0$, $\ldots, \mathrm{n}-1$, dirumuskan sebagai :

Barisan d $\mathrm{d}(\mathrm{x})$ diperoleh lagi dari transformasinya $\mathrm{d}(\mathrm{u})$ dengan menggunakan Inverse Discrete Cosine Transform (IDCT), dirumuskan sebagai berikut [3]:

$$
\begin{aligned}
& d(X)=\sqrt{\frac{2}{n}} \sum_{x=0}^{n-1} d(u) C(u) \cos \left(\frac{(2 x+1) u u}{2 n}\right) \\
& d(X)=\sqrt{\frac{2}{n}} \sum_{x=0}^{n-1} d(u) C(u) \cos \left(\frac{(2 x+1) u u}{2 n}\right)
\end{aligned}
$$

Keterangan : $\mathrm{U}=0, \ldots \ldots \ldots \mathrm{n}-1$

Dimana $\mathrm{C}(\mathrm{u})=2-1 / 2$ untuk $\mathrm{u}=0 \begin{array}{lll}0 & 1 & \text { untuk }\end{array}$ lainnya

Barisan d $\mathrm{d}(\mathrm{x})$ diperoleh lagi dari transformasinya $\mathrm{d}(\mathrm{u})$ dengan menggunakan
Inverse Discrete Cosine Transform (IDCT), dirumuskan sebagai berikut [3]:

$$
d(X)=\sqrt{\frac{2}{n}} \sum_{x=0}^{n-1} d(u) C(u) \cos \left(\frac{(2 x+1) u \mu}{2 n}\right)
$$

Keterangan : $U=0, \ldots \ldots \ldots . n-1$

Dimana $\mathrm{C}(\mathrm{u})=2-1 / 2$ untuk $\mathrm{u}=01$ untuk lainnya Persamaan di atas menyatakan $d$ sebagai kombinasi linier dari basis vector. Koefisien adalah elemen transformasi d, yang mencerminkan banyaknya setiap frekuensi di dalam masukkan d [3].

\section{Discrete Cosine Transform - 2 Dimension}

DCT-2D merupakan perbandingan dari DCT-1D, maka transformasi diskrit dapat dinyatakan dalam bentuk persamaan. Dalam algoritma JPEG, sampel gambar I(i , j) dibagi menjadi blok $8 \times 8$. Setiap blok ditransformasi menjadi 8x8 matriks koefisien DCT. Definisi matematis dari masing-masing blok koefisien didefinisikan sebagai [6]:

$$
d_{u, v}=\frac{c_{u} c_{u}}{4} \sum_{i=0} \sum_{j=0}^{J_{i j}} I_{i j} \cos \left(\frac{(2 i+1) u \pi}{16}\right) \cos \left(\frac{(2 j+1) v \pi}{16}\right)
$$

Dan output dari invers DCT (IDCT) adalah :

$$
\begin{aligned}
& I_{i, j}= \\
& \frac{c_{u} c_{v}}{4} \sum_{u=0}^{7} \sum_{v=0}^{7} d_{u, v} \cos \left(\frac{(2 i+1) u \pi}{16}\right) \cos \left(\frac{(2 j+1) v \pi}{16}\right)
\end{aligned}
$$

Dimana $\mathrm{Cw}$ didefinisikan sebagai

$$
C_{w}=\left\{\begin{array}{l}
\frac{1}{\sqrt{2}}, \text { if } w=0 \\
1, \text { otherwise }
\end{array}\right.
$$

Seperti ditunjukkan pada gambar di bawah ini, matriks koefisien dari blok output DCT disusun sebagai bentuk zigzag. 


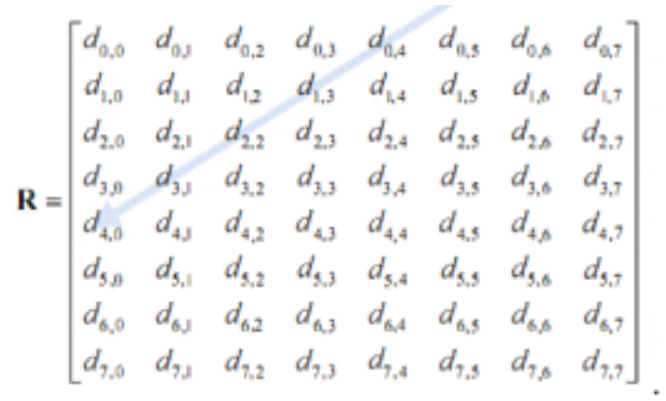

dengan:

$\mathrm{u}=0, \ldots, \mathrm{n}-1$

dimana:

$C(u)=\left\{\begin{array}{l}2^{-1 / 2}, \\ 1\end{array}\right.$

Persamaan di atas menyatakan $s$ sebagai kombinasi linier dari basis vektor. Koefisien adalah elemen transformasi $S$, yang mencerminkan banyaknya setiap frekuensi yang ada didalam masukan $s$ [4].

Discrete Cosine Transform merepresentasi kan sebuah citra dari penjumlahan sinusoida dari magnitude dan frekuensi yang berubahubah. Sifat dari DCT adalah mengubah informasi citra yang signifikan dikonsentrasi kan hanya pada beberapa koefisien DCT. Oleh karena itu DCT sering digunakan untuk kompresi citra seperti pada JPEG. Koefisien discrete cosine transform (DCT) menggambarkan kandungan distribusi frekuensi pada gambar. Transformasinya memiliki sifat yang kompak sedemikian hingga informasi gambar dapat tersimpan dalam sejumlah kecil koefisien hasil transformasi. Untuk alasan praktis, biasanya dipilih ukuran blok yang merupakan kelipatan pangkat 2. DCT bersifat reversible sedemikian hingga koefisien hasil transformasi DCT yang tidak diolah lebih lanjut bisa menghasilkan kembali gambar rekonstruksi sesuai dengan aslinya tanpa cacat. Gambar hasil rekontruksi ini bisa dipandang sebagai kombinasi linear dari fungsi basis DCT. Contoh fungsi basis DCT dua dimensi untuk ukuran matriks yang berbeda akan menghasilkan fungsi basis yang berbeda yang di tampilkan di Gambar 2.3.

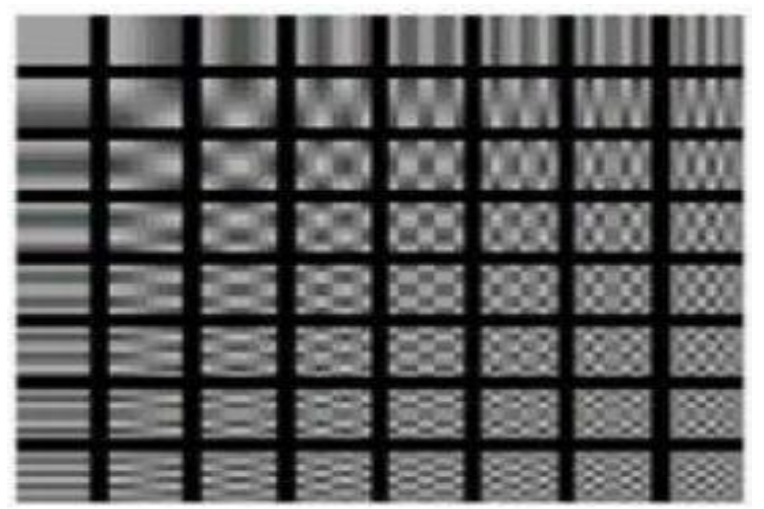

Gambar 3. Base Function DCT 2D (8x 8)

Pada penelitian ini diambil 9 contoh gambar green screen berukuran 300 x 168 . Dari gambar ini dilakukan beberapa proses yaitu:

1. Masing-masing contoh gambar dipisahkan antara objek dengan backup ground secara manual, menghasilkan objek1.

2. Masing-masing contoh gambar dipisahkan antara objek dengan backup ground secara otomatis menggunakan program Matlab dengan metode Greenplate Segmentation, menghasilkan objek2.

3. Dari hasil pemisahan otomatis dengan Greenplate Segmentation objek2 diproses dengan menggunakan metode DCT (Discrete Cosine Transform), menghasilkan objek3.

Sebuah sistem yang melakukan segmentasi tidak bisa bekerja $100 \%$ benar, oleh karena itu harus diukur kinerjanya. Salah satu cara mengukur kinerja segmentasi menggunakan Mean Square Error (MSE).

MSE1 merupakan selisih error antar object1 dikurangi dengan objek2. MSE2 merupakan selisih error antar object1 dikurangi dengan 
object3. Selanjutnya dari MSE1 dan MSE2 keduanya dibandingkan nilainya.

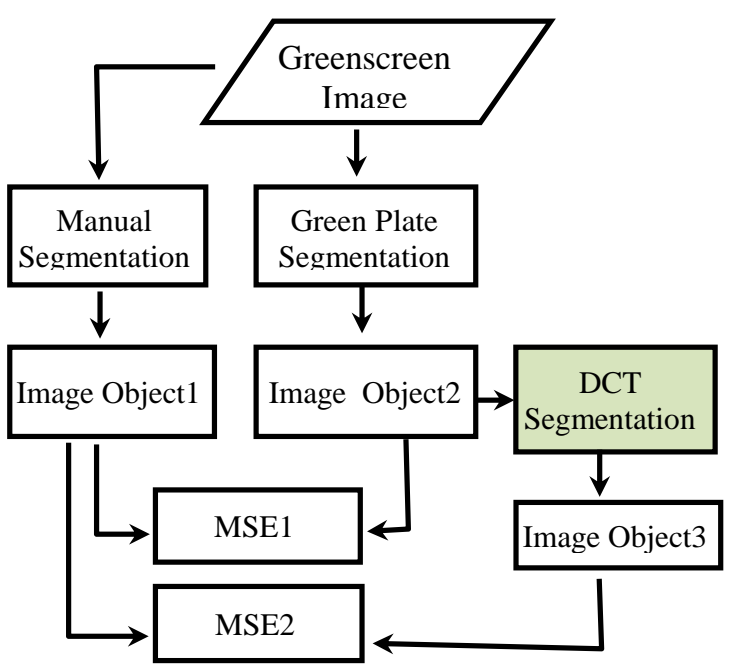

Gambar 4. Tahapan penelitian segmentasi citra

\section{HASIL DAN PEMBAHASAN}

Dari sembilan contoh gambar, maka diperoleh 27 gambar baru. Masing-masing 9 gambar diperoleh dari proses pemisahan object secara manual, 9 gambar yang dipisah melalui proses otomatisasi dengan metode green screen dan 9 gambar yang dipisah melalui proses otomatisasi dengan metode Discrete Cosine Transform.

\section{Pengukuran Kinerja.}

Sebuah sistem yang melakukan segmentasi tidak bisa bekerja $100 \%$ benar, oleh karena itu harus diukur kinerjanya. Salah satu cara mengukur kinerja segmentasi menggunakan Mean Square Error (MSE). Hasil penghitungan dari MSE1 dan MSE2 ditunjukkan pada tabel 1 .

Tabel 1. Perbandingan MSE Greenplate (MSE1) dan MSE DCT (MSE2).

\begin{tabular}{lccc}
\hline Gambar & MSE1 & MSE2 & Selisih \\
\hline Mobil & 7527,1 & 7134,0 & 393,1 \\
Ufo & 943,1 & 2701,4 & 672,7 \\
Cat & 25653,0 & 25650,0 & 3,1 \\
\hline
\end{tabular}

\begin{tabular}{lrrr}
\hline Kuda & 23592,7 & 23586,0 & 6,7 \\
Man & 6306,8 & 6307,5 & 0,7 \\
Gajah & 12046,4 & 12043,7 & 2,7 \\
Harimau & 6161,1 & 6163,2 & 2,1 \\
Pesawat & 23436,1 & 23434,4 & 1,3 \\
Kucing & 8185,8 & 8187,0 & 1,2 \\
\hline
\end{tabular}

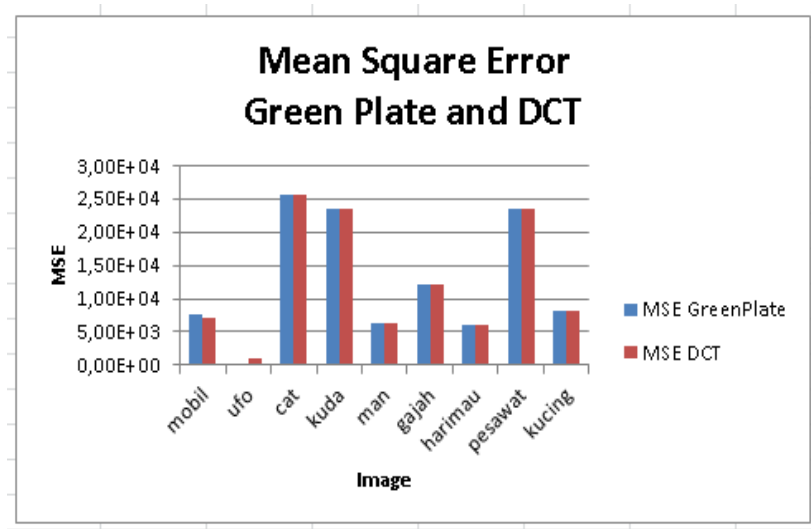

Gambar 5. Grafik MSE Green Plate dan DCT

\begin{tabular}{|c|c|c|c|}
\hline Image & Manual & Greenplate & DCT \\
\hline Mobil & $\Leftrightarrow$ & $\Leftrightarrow$ & $\Leftrightarrow$ \\
\hline Ufo & - & -4 & - \\
\hline Cat & & & a \\
\hline Kuda & & & \\
\hline Man & & & \\
\hline Gajah & ail & สी & aरी \\
\hline Harimau & & $2 \operatorname{sen} 2$ & $\cos 2$ \\
\hline \multicolumn{4}{|l|}{ Pesawat } \\
\hline Kucing & Y & 'x' & 'x' \\
\hline
\end{tabular}

Gambar 6. Perbandingan hasil segmentasi obyek

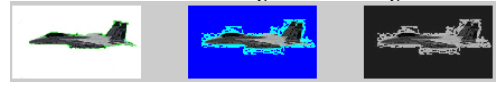

\section{PENUTUP}

Dari hasil ujicoba proses segmentasi citra green screen yang dilakukan dengan penambahan metode Discrete Cosine Transform (DCT) memiliki

Perbandingan Segmentasi Menggunakan Greenplate dan Discrete Cosine Transform pada Obyek Berbasis Greenscreen 
Mean Square Error yang lebih kecil dibandingkan dengan metode greenplate saja. Sehingga dapat disimpulkan dengan menggunakan metode Discrete Cosine Transform dapat memperbaiki segmentasi obyek berbasis green screen.

\section{DAFTAR PUSTAKA}

[1] Hermawati, Pengolahan Citra Digital. Yogyakarta: Penerbit ANDI, 2013.

[2] Erwin Yudi Hidayat and Erika Devi Udayanti, "Hybrid Watermarking Citra Digital Menggunakan Teknik DWT-DCT SVD," in Seminar Nasional Teknologi Informasi \& Komunikasi Terapan, Semarang, 2011.

[3] Shofiyah, "Studi Perbandingan Kompresi Menggunakan Metode Descrete Cosine Transform (DCT) dan Descrete Wavelet Transform (DWT) pada Citra Digital," Skripsi Teknik Informatika Universitas Islam Negeri Maulana Malik Ibrahim, Malang, 2010.

[4] M.H. Purnomo and A Muntasa, Konsep Pengolahan Citra Digital dan Ekstraksi Fitur. Yogyakarta: Graha Ilmu, 2010.

[5] Chung-Ming Kuo, Nai-Chung Yang, Chih-Shan Liu, Jing-Yan $\mathrm{Li}$, and $\mathrm{Fu}-\mathrm{Yan}$ Chen, "Global Image Enhancement in DCT Domain," IEEE, pp. 521-525, 2010. 